\title{
Influence of arterial coronary bypass grafts on the mortality in coronary reoperations
}

From 1988 through 1991, 1663 patients underwent a first reoperation for isolated coronary bypass grafting with $62(3.7 \%)$ in-hospital deaths. At the primary operation, 575 patients had received at least one internal thoracic artery graft and 489 patients had at least one patent internal thoracic artery graft present at the time of reoperation. At reoperation, 1014 patients received at least one internal thoracic artery graft, 10 received an inferior epigastric graft, and 37 received a gastroepiploic graft. Of 489 patients with patent internal thoracic artery grafts at reoperation, the internal thoracic artery was damaged in $17(3.5 \%)$; of $\mathbf{4 2 8}$ patients with a patent internal thoracic artery graft to the left anterior descending coronary artery, $14(3.3 \%)$ had graft damage necessitating regrafting. All patients with damaged internal thoracic arterys survived. Multivariate testing of variables for their association with in-hospital mortality identified no internal thoracic artery graft at either primary surgery or reoperation $(p<0.0001)$, a history of congestive heart failure $(p<0.0001)$, advancing age $(p=0.018)$, female gender $(p=0.029)$, and emergency operation $(p=0.01)$ as factors linked to increased risk. Left ventricular function, left main stenosis, extent of native coronary atherosclerosis, and the interval between operations did not influence mortality. Furthermore, the presence of an atherosclerotic vein graft to the left anterior descending coronary artery a factor shown to increase in-hospital risk in previous studies did not increase risk during these years. We attribute the observation that patent internal thoracic artery and atherosclerotic vein grafts do not appear to be factors specifically increasing the risk of reoperation to the use of retrograde cardioplegic solution and increased surgical experience. The use of internal thoracic artery grafts at a primary operation does not increase the risk of a reoperation, and the use of internal thoracic artery grafts at reoperation does not increase in-hospital morbidity or mortality. (J THORAC CARDIOVASC SURG 1994;107:675-83)

Bruce W. Lytle, MD, Derrick McElroy, MD (by invitation), Patrick McCarthy, MD (by invitation), Floyd D. Loop, MD, Paul C. Taylor, MD (by invitation), Marlene Goormastic, MPH (by invitation), Robert W. Stewart, MD (by invitation), and

Delos M. Cosgrove, MD, Cleveland, Ohio

$\mathrm{R}$ eoperations continue to play an increasing role in coronary artery surgery. The progressive nature of atherosclerosis combined with the excellent long-term survival of patients who have undergone primary coronary bypass operations mean that a large number of patients will eventually have recurrent graft and native vessel stenoses and become candidates for reoperation. To monitor reoperative coronary operations with regard to

From the Department of Thoracic and Cardiovascular Surgery, The Cleveland Clinic Foundation, Cleveland, Ohio.

Read at the Seventy-third Annual Meeting of The American Association for Thoracic Surgery, Chicago, Ill., April 25-28, 1993.

Address for reprints: Bruce W. Lytle, MD, Desk F25, Cleveland Clinic Foundation, 9500 Euclid Ave., Cleveland, $\mathrm{OH} 44195$.

Copyright $\odot 1994$ by Mosby-Year Book, Inc.

$0022-5223 / 94 \$ 3.00+0 \quad 12 / 6 / 52063$ patient population, changing techniques, and surgical results, we have maintained an ongoing series of studies of reoperations. ${ }^{1-5}$ This article reviews the 1663 patients who underwent a first coronary reoperation from 1988 through 1991 and concentrates on two major areas.

One area of focus is on arterial bypass grafting at reoperation and the relationship between the use of arterial grafts and perioperative risk. Studies of primary coronary bypass operations have clearly documented the short- and long-term superiority of the strategy of using the left internal thoracic artery (ITA) over the grafting of the left anterior descending coronary artery (LAD) ${ }^{6-8}$ As the use of arterial grafts at primary operations has been extended, further studies ${ }^{9}, 10$ and unpublished data* sug-

*Cosgrove DM, Lytle BW, Hill AC. Are two internal thoracic arteries better than one? Unpublished data. 
Table I. Clinical characteristics of patients undergoing reoperation according to year of reoperation

\begin{tabular}{lccccc}
\hline Year of reoperation & $1967-78$ & $1979-81$ & $1982-84$ & $1985-87$ & $1988-91$ \\
No. of patients & 436 & 439 & 625 & 1009 & 1663 \\
Male gender & $91 \%$ & $87 \%$ & $85 \%$ & $88 \%$ & $85 \%$ \\
Mean age (yr) & & & & 53 & 53 \\
$\quad$ First operation & 49 & 50 & 51 & 50 & 63 \\
$\quad$ Second operation & 52 & 56 & 84 & 101 & 116 \\
Interval between operations (mo) & 50 & 72 & & 9 & 8 \\
Age decade at reoperation (\%) & 29 & 20 & 14 & 32 & 23 \\
$\quad<50$ & 49 & 46 & 40 & 45 & 48 \\
$50-59$ & 21 & 30 & 3 & 14 & 21 \\
\hline $0-69$ & 1 & 3 & & & \\
\hline 70 & & & & & \\
\hline
\end{tabular}

gest some advantages of using bilateral ITA grafts in selected subsets of patients. Many authors have described the use of ITA grafts at reoperation, ${ }^{2,3,11-14}$ but no study has placed arterial bypass grafting in the context of a large, consecutive series of patients undergoing reoperation or examined in detail the perioperative risk associated with arterial bypass grafting at reoperation.

A second goal of this study is to examine the impact of preoperative graft status on risk. Most patients undergoing coronary reoperation have at least part of the myocardium dependent on atherosclerotic vein grafts or patent ITA grafts-situations that complicate myocardial protection..$^{15}$ There has long been concern that the presence of patent ITA grafts might increase the risks of reoperation. Furthermore, in a previous study of patients with stenotic vein grafts, we found that the presence of vein graft atherosclerosis in a graft to the LAD coronary artery increased operative mortality. ${ }^{4}$ The years of the present study coincide with the initiation and consistent use of retrograde coronary sinus cardioplegic solution during reoperations, allowing the assessment of the effectiveness of retrograde cardioplegic solution delivery in the treatment of patients undergoing repeat bypass operations. ${ }^{16-18}$

\section{Patients and methods}

With the aid of a computerized cardiovascular information registry, we identified a consecutive series of 1663 patients who underwent a first reoperation for isolated coronary artery bypass grafting at the Cleveland Clinic Foundation from 1988 through 1991. Patients who had undergone more than one previous cardiac operation or who had had non-coronary artery procedures as part of their previous or present operation were excluded. These patients were compared in some analyses with cohorts of 2509 patients examined in previous studies of patients undergoing reoperation for isolated coronary bypass grafting. ${ }^{3}$ Variables tested for their influence on in-hospital results are listed in Appendix 1. "In-hospital" death is defined as death before hospital discharge, regardless of the duration of the hospitalization. univariate comparisons were performed with a Pearson $\chi^{2}$ test on categorical factors. Differences between groups in mean lev- els of continuous variables were tested with an unpaired $t$ test. Stepwise logistic regression analysis was used to test for factors associated with hospital death and morbidity. ${ }^{19}$ All analyses were performed with Statistical Analysis System (SAS) software. ${ }^{20}$ Alpha levels less than or equal to 0.05 were considered to be statistically significant.

The word "patent" refers to bypass grafts that were not totally occluded and includes stenotic grafts. The phrase "patent without stenoses" refers to grafts with no angiographic narrowing of $20 \%$ or more. Numbers of ITA grafts refer only to use of the left and right ITA to construct bypass grafts regardless of the number of distal anastomoses: when an ITA was used for a sequential graft, it still was considered one graft.

This is a retrospective study, and no randomization of any kind was carried out. During the years under review, myocardial protection was accomplished with the use of cold cardioplegic solution. Both oxygenated crystalloid and blood cardioplegic solution were used at the discretion of the surgeon. Retrograde coronary sinus delivery of cardioplegic solution through a transatrial cannula was used in most cases, and delivery protocols varied according to surgeon and case.

Patient population. Patient gender, age, and mean interval between operations are listed in Table I, and the present group of patients is compared with previous cohorts of patients undergoing reoperation. The most dramatic change is the increase in the numbers of patients over 70 years of age. In comparison with the most recent previous cohort (1985 to 1987), the mean age at the first operation was similar for the present group; however, the interval between operations was longer by more than 1 year (116 versus 101 months), and the mean age at the second operation was 3 years older.

The angiographic characteristics of patients undergoing reoperation have continued to evolve in the directions of abnormal left ventricular function, left main stenosis, multivessel disease, and graft failure as an indication for reoperation. In comparison with our original cohort of patients undergoing reoperation (1967 to 1978) the percentage of the current study group with each characteristic were normal left ventricular function, $60 \%$ versus $28 \%$; left main stenosis, $12 \%$ versus $27 \%$; single or double vessel disease, $37 \%$ versus $12 \%$; and graft failure as at least part of the angiographic indications for reoperation, $45 \%$ versus $92 \%$ (all $p<0.0001$ ).

Arterial grafts. At least one ITA graft was used at reoperation in 1014 patients. Of the 1088 patients who received no ITA grafts at their first operation, $799(73 \%)$ received at least one ITA graft during reoperation, and $126(12 \%)$ received bilateral 
Table II. ITA grafts at primary operation/ITA grafts at reoperation: in-hospital mortality, baseline descriptions

\begin{tabular}{|c|c|c|c|c|c|c|c|}
\hline Group* & $I(0 / 0)$ & $2(0 / I)$ & $3(0 / 2)$ & $4(1 / 0)$ & $5(I / 1)$ & $6(2 / 0)$ & $\mathrm{p}$ Value \\
\hline No. of patients & 289 & 673 & 126 & 345 & 215 & 15 & \\
\hline \multicolumn{8}{|l|}{ Mortality } \\
\hline No. & 23 & 16 & 2 & 16 & 4 & 1 & \\
\hline$\%$ & 8.0 & 2.4 & 1.6 & 4.6 & 1.9 & 6.7 & $<0.001$ \\
\hline Mean age (yr) & 67.4 & 63.2 & 56.2 & 63.2 & 58.9 & 54.7 & $<0.001$ \\
\hline$\%>70$ yr & 40.8 & 19.8 & 1.6 & 20.0 & 10.7 & 0.0 & $<0.001$ \\
\hline$\%$ Women & 20.4 & 11.9 & 5.6 & 20.0 & 11.6 & 33.3 & $<0.001$ \\
\hline$\%$ Emergency & 5.2 & 1.5 & 0.8 & 2.6 & 0.0 & 13.3 & $<0.001$ \\
\hline$\% \mathrm{CHF}$ & 12.8 & 10.8 & 4.8 & 8.7 & 7.4 & 26.7 & 0.017 \\
\hline \% Diabetes & 19.0 & 20.1 & 7.1 & 19.7 & 16.3 & 20.0 & 0.02 \\
\hline
\end{tabular}

$C H F$, History of congestive heart failure.

${ }^{*}$ Ratio in parentheses is number of ITAs used for grafting at primary operation/number of ITAs used for grafting at reoperation.

Table III. Use of right ITA bypass grafts for patients with patent left ITA-to-LAD grafts*

\begin{tabular}{cccc}
\hline & \multicolumn{3}{c}{ No. of vessels grafted } \\
\cline { 2 - 4 } Type of right & LAD-diagonal & & \\
ITA graft & system & $C x$ & $R C A$ \\
\hline In situ & 23 & 22 & 46 \\
Free & 6 & 35 & 10
\end{tabular}

$C x$, Circumflex artery, $R C A$, right coronary artery; Free, aorta-to-coronary graft. *Indication for regrafting the LAD-diagonal system were a stenosis in the left ITA graft or progression of native coronary disease in the distal LAD or a diagonal branch.

ITA grafts. Of 560 patients who had received one ITA graft at their first operation, $215(38 \%)$ received a second ITA graft at reoperation.

Subgroups of patients grouped according to the number of ITAs used for bypass grafting at their primary operations and at their reoperations are shown in Table II with the in-hospital mortality for those subgroups and the prevalence of selected patient-related variables in each subgroup. Patients in the subgroup who received no ITA grafts at either the primary operation or reoperation were significantly more likely to be women, be over 70 years of age, have a history of congestive heart failure, and undergo emergency reoperations.

Patent ITA grafts were present in 489 patients at reoperation, and patent ITA grafts to the LAD were present in 428 patients. In reoperations for patients with patent ITA-LAD grafts, the right ITA was used as a graft in 142 cases. The vessels grafted with the right ITA and the type of graft used (in situ versus free graft) for this subset of patients are shown in Table III.

The right gastroepiploic artery was used as a graft for 37 patients, 33 times as an in situ graft ( 23 to the right coronary artery, six to circumflex, four to LAD), and in four patients as a free graft. In 10 patients, the inferior epigastric artery was used as a free graft, all to the $\mathrm{LAD}$ or a diagonal branch. One patient received an right gastroepiploic artery graft as the only arterial graft at reoperation, 14 received an right gastroepiploic artery or inferior epigastric artery graft in association with a single ITA graft and 30 in association with bilateral ITA grafts.
Table IV. Cause of death at reoperation

Cardiovascular
Myocardial infarction
Cerebrovascular accident
Arrhythmia
Embolic shower*
Ruptured abdominal aortic aneurysm
Total
Noncardiovascular
Gastrointestinal bleeding
Multisystem failure
Renal failure
Sepsis
Total

*Documented atherosclerotic embolization (presumably from the aorta) to noncardiac organs causing multiorgan failure.

\section{Results}

In-hospital mortality. There were $62(3.7 \%)$ in-hospital deaths. The causes of death are listed in Table IV. Cardiovascular causes accounted for 53 deaths $(85 \%)$ and 41 were due to new myocardial infarction. Of the 41 patients who died of myocardial infarction, postmortem examinations were performed for 27 . Vein graft thrombosis was documented in 15 patients, occlusion of an ITA graft in one and eight patients had patent grafts but distal disease in native coronary vessels. Two patients underwent operation with evolving preoperative myocardial infarction and one myocardial infarction was caused by a retained catheter after percutaneous transluminal coronary recanalization. Atherosclerotic embolization to coronary arteries was not reported in any patient.

The variables in Appendix 1 were examined with univariate and multivariate analyses to identify factors associated with in-hospital mortality. Data regarding univariate analyses of selected variables are contained in Tables II, V and VI. Logistic regression analysis identi- 
Table V. Univariate analysis of the influence of selected patient-related variables on in-hospital mortality

\begin{tabular}{lcccc}
\hline & $\begin{array}{c}\text { No. of } \\
\text { patients }\end{array}$ & Deaths & $\begin{array}{c}\text { Mortality } \\
\text { (\%) }\end{array}$ & p Value \\
\hline Gender & & & & \\
Male & 1418 & 44 & 3.1 & \\
Female & 245 & 18 & 7.4 & 0.001 \\
Age (yr) & & & & \\
$<50$ & 130 & 0 & & \\
50-59 & 386 & 10 & 2.6 & \\
$60-69$ & 802 & 32 & 4.0 & 0.009 \\
$70-79$ & 331 & 18 & 5.4 & \\
$\geq 80$ & 14 & 2 & 14.3 & \\
History CHF & & & & \\
Yes & 166 & 15 & 9.0 & \\
No & 1497 & 47 & 3.1 & $<0.001$ \\
Left ventricular function & & & \\
Normal & 463 & 11 & 2.4 & \\
Mild & 548 & 21 & 3.8 & 0.01 \\
Moderate & 473 & 17 & 3.6 & \\
Severe & 144 & 12 & 8.3 & \\
Emergency operation & & & \\
Yes & 37 & 5 & 13.5 & \\
No & 1626 & 57 & 3.5 & 0.001 \\
Interval between operations & & & \\
$\quad<5$ years & 193 & 7 & 3.6 & NS \\
5-10 years & 666 & 24 & 3.6 & \\
$>$ 10 years & 804 & 31 & 3.9 & \\
\hline
\end{tabular}

CHF, Congestive heart failure; $N S$, not significant.

fied the factors associated with an increased mortality as no ITA graft at either primary operation or reoperation $(p<0.0001)$, a history of congestive heart failure ( $p<0.0001)$, emergency operation $(p=0.01)$, advanced age $(p=0.018)$, and female gender $(p=0.029)$. The increase in mortality with age was due entirely to an increased risk for older women. For men, risk increased with age only slightly (Fig. 1).

Selected subsets of patients grouped according to graft status before reoperation and their in-hospital mortality rates are shown in Table VI. None of these subsets were significantly associated with in-hospital mortality.

In-hospital morbidity. Table VII lists morbidity according to the subgroups determined by the number of ITA grafts at the first and second operations. The variables in Appendix 1 were tested for their influence on morbidity and logistic regression analysis did not identify any association between numbers of ITAs received at the first or second operation, or both, and the occurrence of morbidity. The factors associated with the occurrence of in-hospital complications were New York Heart Association functional class $(p=0.0001)$, emergency operation $(p=0.0004)$, age $(p=0.0008)$, history of cerebrovascu- lar accident $(p=0.002)$, and extent of disease $(p=0.009)$. Damage to a patent ITA graft necessitating graft replacement occurred in 17 of 489 patients (3.5\%) with patent ITA grafts and 14 of 428 patients with patent ITA to LAD grafts. All patients with damaged ITA grafts survived.

\section{Discussion}

The numbers of patients undergoing coronary reoperations continues to increase. Patient-related characteristics of reoperative candidates continue to evolve in directions noted in previous studies. ${ }^{1-3}$ The average age of candidates who underwent reoperation has increased, as has the percentage of patients over 70 years of age-now $21 \%$ of the total. The interval between operations is now about 10 years, and virtually all patients have graft failure as part of the angiographic indications for reoperation. Normal left ventricular function is increasingly uncommon, present in only $28 \%$ of cases during the 1988 to 1991 time frame.

One of the goals of this study was to examine the risk of reoperation as related to the status of the grafts done at the primary operation. The many patients undergoing reoperation who have atherosclerotic stenoses in vein grafts are at risk for embolization of atherosclerotic debris to distal coronary arteries, a phenomenon well documented as a cause of perioperative myocardial infarction. ${ }^{21,22}$ On the other hand, immediate ligation of stenotic vein grafts, as has been suggested, ${ }^{23}$ makes delivery of antegrade cardioplegic solution difficult and risks devascularizing areas of myocardium. In a previous study of patients with late stenoses in vein grafts who underwent reoperation, we found that the presence of a late stenosis in an LAD vein graft was a factor that specifically increased in-hospital mortality. ${ }^{4}$ Other investigators have noted compatible results. Salomon and associates ${ }^{15}$ found that the risk of reoperation increased as the interval between operations increased, particularly if that interval exceeded 10 years. Postoperative interval correlates with the likelihood of atherosclerotic stenoses in vein grafts. Perrault and associates ${ }^{16}$ noted in-hospital mortality of $7 \%$, $17 \%$, and $29 \%$ for patients with one, two, and three or more patent but atherosclerotic vein grafts, respectively. Furthermore, when comparing three different strategies for the delivery of antegrade cardioplegic solution, they were unable to demonstrate that any of them were consistently effective.

For the patients in this study, the presence of patent but atherosclerotic vein grafts did not increase mortality. Risk increased slightly for patients with multiple stenotic vein grafts, but this did not reach statistical significance with either univariate or logistic regression testing. Multiple 


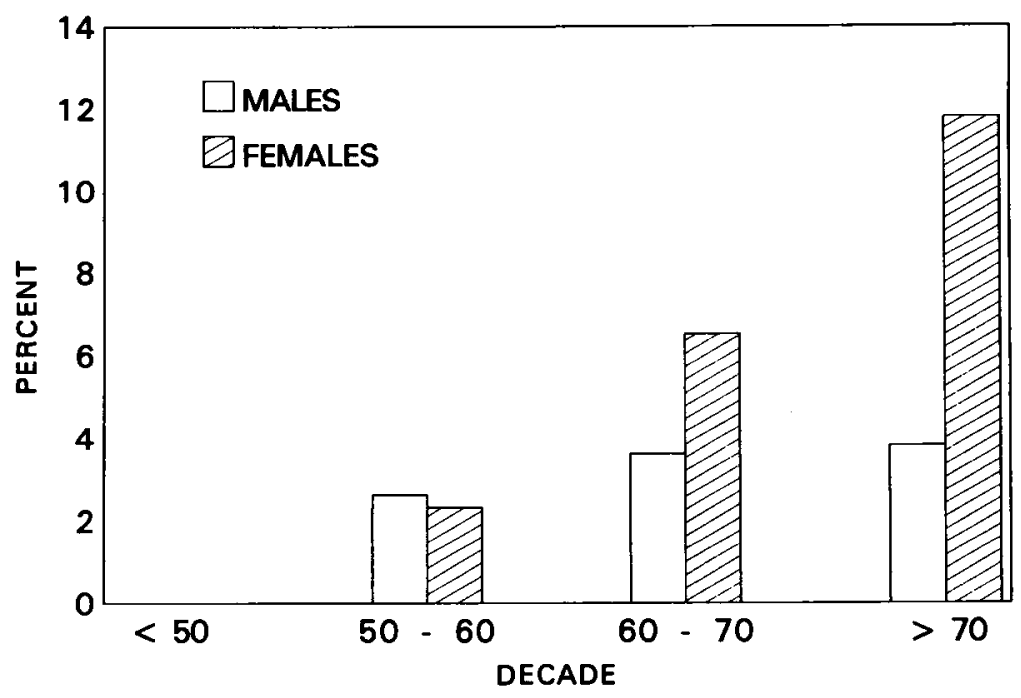

Fig. 1. Increased mortality with increasing age was almost entirely dependent on an increased risk for older women (11.8\% mortality for women over 70 years of age). Men had only a slight increase in mortality with age.

Table VI. Selected angiographic subsets of patients on the basis of preoperative graft status and mortality

\begin{tabular}{|c|c|c|c|c|}
\hline & No. of patients & Deaths & Mortality (\%) & $\mathrm{p}$ Valuet \\
\hline Patent $(<100 \%)$ ITA-to-LAD & 428 & 16 & 3.7 & 0.99 \\
\hline $\begin{array}{l}\text { Patent ITA-to-LAD graft, right ITA used for graft at } \\
\text { reoperation }\end{array}$ & 142 & 3 & 2.1 & 0.28 \\
\hline All grafts occluded & 266 & 13 & 4.9 & 0.28 \\
\hline \multicolumn{5}{|l|}{ Late $(\geq 5 \mathrm{yr})$ SVG stenosis $(50 \%-99 \%)^{*}$} \\
\hline 1 SVG stenotic & 574 & 22 & 3.8 & \\
\hline$\geq 2$ SVG stenotic & 130 & 8 & 6.1 & 0.13 \\
\hline SVG-LAD stenotic & 307 & 11 & 3.6 & \\
\hline
\end{tabular}

$I T A$, Internal thoracic artery; $L A D$, left anterior descending coronary artery; $S V G$, saphenous vein graft.

*Patients without patent ITA grafts.

$p$ Value versus the entire study.

strategies have been proposed for dealing with atherosclerotic vein grafts, and increasing experience enables the surgeon to more appropriately adjust these principles to individual cases. We believe, however, that the use of retrograde coronary sinus cardioplegic solution is a technical advance that has had an impact on the safety of reoperations for patients with atherosclerotic vein grafts above and beyond the effect of increased surgical experience. Cold cardioplegic solution was used for the patients in this study, and both antegrade and retrograde delivery was used in most cases. The use of retrograde delivery of cardioplegic solution allows the maintenance of cardioplegic arrest even when atherosclerotic vein grafts have been divided to prevent embolization of atherosclerotic debris. Not only does retrograde delivery allow maintenance of hypothermia and arrest, but we have observed on multiple occasions retrograde cardioplegic solution flow forcing atherosclerotic debris out an open coronary arteriotomy. Retrograde delivery of cardioplegic solution appears to diminish the likelihood of embolization and also can be used to treat that complication. None of the patients who died of myocardial infarction and had postmortem examinations had atherosclerotic embolization in the coronary system.

An important lesson that experience in the treatment of patients with stenotic vein grafts has taught us is not to replace a patent or stenotic vein graft with an ITA graft alone. If an area of myocardium is dependent on a vein graft and that graft is disconnected, an ITA graft that is used to replace it may not provide enough flow initially, and catastrophic hypoperfusion can result. Jones, Lattouf, and Weintrab ${ }^{24}$ have reported this complication, and we have noted it anecdotally in the past. Navia and associates $^{25}$ recently reviewed our experience with this situa- 
Table VII. Ratio of morbidity according to number of ITA grafts at primary operation/number of ITA grafts at reoperation

\begin{tabular}{lccccccc}
\hline & $0 / 0$ & $0 / 1$ & $0 / 2$ & $1 / 0$ & $1 / 1$ & $2 / 1$ & Total \\
\hline No. of patients & 289 & 673 & 126 & 345 & 215 & 15 & 1663 \\
MI & & & & & & & \\
No. & 24 & 39 & 10 & 24 & 14 & 0 & 111 \\
$\%$ & 8.3 & 5.8 & 7.9 & 7.0 & 6.5 & 0 & 6.7 \\
$\begin{array}{l}\text { Bleeding } \\
\text { No. }\end{array}$ & 17 & 27 & 4 & 15 & 6 & 2 & 71 \\
$\%$ & 5.9 & 4.0 & 3.2 & 4.3 & 2.8 & 13.3 & 4.3 \\
CVA & & & & & & & \\
No. & 13 & 20 & 2 & 10 & 3 & 0 & 48 \\
$\%$ & 4.5 & 3.0 & 1.6 & 2.9 & 1.4 & 0 & 2.9 \\
Respiratory complications & & & & & & \\
No. & 30 & 53 & 7 & 33 & 15 & 1 & 139 \\
$\%$ & 10.4 & 7.9 & 5.6 & 9.6 & 7.0 & 6.7 & 8.4 \\
Wound & \multicolumn{1}{c}{} & & & & & & \\
No. & 4 & 10 & 2 & 5 & 2 & 0 & 23 \\
$\%$ & 1.4 & 1.5 & 1.6 & 1.4 & 0.9 & 0 & 1.4 \\
\hline
\end{tabular}

$M I$, Myocardial infarction with electrocardiogram changes; Bleeding, reoperation for hemorrhage or tamponade; $C V A$, cerebrovascular accident before discharge.

tion and found that the strategy of interrupting a stenotic vein graft to the $\mathrm{LAD}$ and replacing it with an ITA graft resulted in a $19 \%$ prevalence of hypoperfusion, often with serious consequences. The alternative management strategies, including grafting the LAD with an ITA graft while leaving the old vein graft intact, replacing the vein graft with a new vein graft, and grafting a diagonal with a vein graft in addition to an ITA-to-LAD graft, all have theoretical disadvantages but resulted in better initial outcomes.

Despite concern about the technical difficulties of reoperation for patients with patent ITA grafts, we have never identified that subgroup as being at increased risk during repeat operation. ${ }^{2,3}$ There may be multiple explanations for this. Patients receiving ITA grafts at primary operation may have more favorable patient-related characteristics. The excellent long-term patency rate of ITA grafts means that most patients receiving ITA grafts at primary operation come to reoperation with good anterior wall function. Lastly, atherosclerotic embolization does not occur from patent ITA grafts. Despite the technical challenge of treating patients with patent ITA grafts, those patients have not been at increased risk during reoperation.

However, patients with patent ITA grafts also benefit from retrograde cardioplegia. Before to the advent of retrograde cardioplegia, we achieved myocardial protection to ITA-dependent myocardium by using systemic hypothermia and leaving the ITA graft unclamped. That strategy worked well but requires more time for cooling and rewarming and may result in suboptimal exposure of coronary arteries as a result of collateralized blood from the patent ITA graft. Retrograde cardioplegia is much more convenient. With the use of retrograde cardioplegia, the ITA graft can be dissected out and temporarily clamped while cardioplegic arrest is maintained by intermittent retrograde delivery.

Although the risk of mortality does not appear to have been lowered for patients with patent ITA grafts (beyond its already low level), increased experience has decreased the risk of ITA damage. In our first 100 consecutive reoperations for patients with patent ITA grafts, eight ITA grafts were damaged and required regrafting, ${ }^{26}$ whereas, in the present series of patients, that adverse event occurred in only $3.7 \%$ of patients with patent ITA grafts.

Despite the increased effectiveness of delivery of cardioplegic solution with retrograde techniques, the risk of perioperative myocardial infarction has not been eliminated, probably because perioperative myocardial infarction has a multiplicity of causes, some of which are related to anatomy. Anatomic causes of perioperative myocardial infarction include incomplete revascularization, graft thrombosis, technical error, embolization of atherosclerotic debris from the aorta or atherosclerotic vein grafts, graft injury, and native coronary thrombosis. Occurrence of these anatomic events can cause perioperative myocardial infarction even in the face of effective techniques of intraoperative myocardial protection. Perioperative myocardial infarction was still the predominant cause of death in this study. Of the 41 patients who died with new myocardial infarction, $27(66 \%)$ underwent postmortem examination. Fifteen of these patients were found to have vein graft thrombosis, and virtually all those patients had diffuse native coronary artery disease in the area subtended by the graft. Obvious technical errors were not apparent in the patients examined. One patient had a failed ITA graft. In addition, eight patients died with myocardial infarction without graft occlusion, and, again, all had diffuse distal native coronary artery disease.

In this study, graft selection was made according to the judgment of the surgeon and decisions about the use of arterial grafts at reoperation are more complex than similar decisions in the setting of primary operation. Some factors involved in graft selection were made obvious by the analyses of the distribution of patient-related variables among the ITA graft subgroups, and there were almost certainly many more selection criteria that were not statistically obvious. The subgroup of patients receiving no ITA grafts at either operation contained signifcantly higher numbers of women, patients over 70 years of age, patients undergoing emergency operation, and 
patients with a history of congestive heart failure. These factors were identified as patient-related variables increasing mortality. In other words, that graft subgroup contained a high-risk group of patients. Despite the fact that logistic regression analysis, designed to adjust for patient-related variables, appeared to identify no ITA graft at either the first or second operation as a factor associated with increased mortality, we still are not completely convinced that it was the strategy of avoiding the use of an ITA graft that increased risk. The biases in graft selection were so profound that we do not think they can be eliminated with retrospective multivariate analysis.

On the other hand, it does appear that with judicious criteria of selection, the majority of patients undergoing reoperation can receive arterial grafts with no increase in surgical risk. These selection criteria were obviously fairly broad because almost three fourths of patients who did not receive an ITA graft at primary operation received at least one ITA graft during reoperation, and almost $40 \%$ of those who received one ITA graft at their initial procedure received a second ITA graft at reoperation. Reoperative bilateral ITA grafting and the use of a second ITA graft for patients who received one ITA at primary operation were strategies associated with particularly low reoperative risk.

Not only was there no increase in mortality associated with arterial grafting, but there did not appear to be an increase in morbidity either. It is of particular interest that sternal wound complications were uncommon. In a previous review of wound complications (1985 to 1987), we found an overall prevalence of wound complication at reoperation of $1.5 \%,{ }^{27}$ which is almost exactly the $1.4 \%$ in this study. In that previous study, the use of bilateral ITA grafts at reoperation had a prevalence of wound complication of $2.7 \%$. The $1.6 \%$ wound complication rate for the patients receiving bilateral ITA grafts at reoperation in the present study may be related to the fact that few patients with diabetes, a subgroup more prone to wound complications in the setting of bilateral ITA grafts, received bilateral ITA grafts. Wound complications occurred for only $2(0.9 \%)$ of 215 patients who had staged (one at primary operation, one at reoperation) use of both ITAs for bypass grafts, and, at present, we use that strategy in patients with and without diabetes. There are many advantages of using ITA grafts at reoperation. They usually are available, and they may not require a proximal anastomosis, something that may be a consideration if extensive scarring as a result of the primary operation produces limited accessibility to the ascending aorta. Data documenting the long-term advantages of ITA grafts, particularly when used to the left anterior descending coronary artery, are overwhelming, and although those data have been derived almost entirely from studies of patients undergoing primary bypass operation, there is no reason to believe that the principles differ for patients undergoing reoperation. Furthermore, in our last review of the long-term results of reoperative operation, there did appear to be a long-term survival advantage for patients with an ITA graft. ${ }^{3}$

We have used alternative arterial grafts, the inferior epigastric artery and the right gastroepiploic artery, in increasing numbers. The inferior epigastric artery is usually a vessel with favorable handling characteristics, but we have limited its use at reoperation to patients without other available conduits because of the lack of long-term patency data. On the other hand, the right gastroepiploic artery has less favorable handling characteristics and is less consistent in size, but it can be used as an in situ graft at reoperation and has the favorable medium-term patency data noted by Suma and associate ${ }^{28}$ supporting its use. We are now using the right gastroepiploic artery as an in situ graft at reoperation electively for some patients with vein graft failure.

Patients who are now candidates for reoperation usually have survived for long periods of time after their primary operation. The native coronary artery disease that indicated their initial operation combined with the longterm effect of their atherogenic diathesis often produce extremely diffuse native coronary artery disease at the time of reoperation. Arterial grafts are usually an appropriate choice for the treatment of these patients. This study indicates that use of arterial grafts does not appear to increase the risk of reoperation.

We acknowledge the technical and statistical assistance of Maura J. Schnauffer.

\section{REFERENCES}

1. Loop FD, Cosgrove DM, Kramer JR, et al. Late clinical and arteriographic results in 500 coronary artery reoperations. J ThORAC CARDIOvasC SuRg 1981;81:675-85.

2. Lytle BW, Loop FD, Cosgrove DM, et al. Fifteen hundred coronary reoperations: results and determinants of early and late survival. J THORAC CARdiovasc SuRg 1987; 93:847-59.

3. Loop FD, Lytle BW, Cosgrove DM, et al. Reoperation for coronary atherosclerosis: Changing practice in 2509 consecutive patients. Ann Surg 1990;212:378-86.

4. Lytle BW, Loop FD, Taylor PC, et al. The effect of coronary reoperation on the survival of patients with stenoses in saphenous vein to coronary bypass grafts. J THORAC CARDIOVASC SURG 1993;105:605-14.

5. Lytle BW and Loop FD. Coronary reoperations. Surg Clin North Am 1988;68:559-80.

6. Lytle BW, Loop FD, Cosgrove DM, Ratliff NB, Easley K, 
Taylor PC. Long-term (5 to 12 years) serial studies of internal mammary artery and saphenous vein coronary bypass grafts. J THORAC CARDIOVASC SURG 1985;89:24858.

7. Loop FD, Lytle BW, Cosgrove DM, et al. Influence of the internal-mammary-artery graft on 10-year survival and other cardiac events. N Engl J Med 1986;314:1-6.

8. Sargeant $P$, Lasaffre E. Flameny $W$, et al. Internal mammary artery: methods of use and their effect on survival. Eur J Cardiothorac Surg 1990;4:72-8.

9. Dion R, Verheist R, Rousseau M, et al. Sequential mammary grafting. clinical, functional and angiographic assessment 6 months postoperatively in 231 consecutive patients. J Thorac Cardiovasc Surg 1989;98:80.

10. Galbut DL, Traad EA, Durman MJ, et al. Seventeen-year experience with bilateral internal mammary artery grafts. Ann Thorac Surg 1990;99:195.

11. Galbut DL, Traad EA, Dorman MJ, et al. Bilateral internal mammary artery grafts in reoperative and primary coronary bypass surgery. Ann Thorac Surg 1991;52:20-8.

12. Mills NL, Everson CT, Hockmuth DR. Technical considerations for myocardial protection during he course of coronary artery bypass reoperation: the impact of functioning saphenous vein and internal mammary artery grafts. J Card Surg 1991;1:34.

13. Nuyez L, VanderWerf F, Janssen DPD et al. Early results with bilateral internal mammary artery grafting in coronary reoperations. Am J Cardiol 1991;70:1113-6.

14. Salomon NW, Psage US, Bigelow JC, et al. Reoperative coronary surgery: comparative analysis of 6591 patients undergoing primary bypass and 508 patients undergoing reoperative coronary bypass. J THORAC CARDIOvasC SURG 1990;100:250-60.

15. Perrault L, Carrier M, Cartier R., et al. Morbidity and mortality of reoperation for coronary artery bypass grafting: significance of atheromatous vein grafts. Can J Cardiol 1991;7:427-430.

16. Menasché P, Kural S, Fanchet M, et al. Retrograde coronary sinus perfusion: a safe alternative for ensuring cardioplegic delivery in aortic valve surgery. Ann Thorac Surg 1982;34:649.

17. Gundry SR, Razzouk AJ, Vigesaa RE, et al. Optimal delivery of cardioplegic solution for "redo" operations. J Thorac CardiovasC SURG 1991;103:896-901.

18. Loop FD, Higgins TL, Panda R, et al. Myocardial protection during cardiac operations. decreased morbidity and lower cost with blood cardioplegia and coronary sinus perfusion. J THORAC Cardiovasc SuRg 1991;104:608-18.

19. Cox DR. The analysis of binary date. London. Chapman \& Hall, 1970.

20. SAS Institute Inc. SAS/STAT User's Guide, Version 6, 4th ed. Cary, N.C.: 1989.

21. Jain U, Sullivan HJ, Pifarre R, et al. Graft atheroembolism as the probable cause of failure to wean from cardiopulmonary bypass. J Cardiothoracic Anesthesia 1990;4:476-80.

22. Keon WJ, Heggtveit HA, Lecluc J. Perioperative myocardial infarction caused by atheroembolization. J THORAC CARDIOVASC SURG 1982;84:849-55.
23. Grondin CM, Pomar JL, Hebert Y, et al. Reoperation in patients with patent atherosclerotic coronary vein grafts: a different approach to a different disease. J THORAC CARDIOVASC SURG 1984;87:379-85.

24. Jones EL, Lattouf OM, Weintraub WS. Catastrophic consequences of internal mammary artery hypoperfusion. $\mathbf{J}$ Thorac Cardiovasc Surg 1989;98:902-7.

25. Navia D, Cosgrove DM, Lytle BW, et al. Is the internal thoracic artery the conduit of choice to replace a stenotic vein graft? Ann Thor Surg [In press].

26. Baillot RG, Loop FD, Cosgrove DM, Lytle BW. Reoperation after previous grafting with the internal mammary artery: technique and early results. Ann Thorac Surg 1985;40:271-3.

27. Loop FD, Lytle BW, Cosgrove DM, et al. Sternal wound complications after isolated coronary artery bypass grafting: early and late mortality, morbidity and cost of care. Ann Thorac Surg 1990;49:179-87.

28. Suma H, Wanibuchi $Y$, Terada $Y$, et al. The right gastroepiploic artery graft: clinic and angiographic midterm results in 200 patients. J Thorac Cardiovasc SuRG 1993;105:615-23.

\section{Discussion}

Dr. Tjark Ebels (Groningen, The Netherlands). I entirely agree with your conclusions. However, I would like to extend your conclusions and say a few words about its implications. One element that you did not focus on, at least not in the figures from the abstract, is that $85 \%$ of your internal mammary arteries were patent. I do not know how long the follow-up was after the primary operation; nevertheless, I think that further strengthens the support for the use of ITA grafts. Some among us, however, still maintain that ITA grafts should not be used in young patients but preserved, that is, preserved for the reoperation. This, in my opinion, is obviously a self-fulfilling prophecy.

Second, ITA grafts, so it is maintained, increase the risk at a possible reoperation, and I think you have refuted this presumption in the paper you just presented. You demonstrated well that the presence of an open ITA graft is a favorable factor for survival in reoperation. This means to me that arterial grafts should be used, especially in young patients, to give them the best chance for their future.

My question therefore is, do you agree with me that in the choice of graft conduit, especially in young patients, one should use the ITA and, maybe somewhat provocatively, arterial grafts in general instead of venous grafts?

Dr. Ahmad Rajaii-Khorasani (Neptune, N.J.). Redo coronary bypass in patients with patent mammary grafts presents two challenges. The first is the challenge of dissection, and the second is the challenge of cardioplegia. In regard to the first challenge, there are three areas where the surgeon should be more careful to avoid injury to the ITA graft: (1) at the time of sternotomy when the oscillating saw is used, (2) when the soft tissues of the mediastinum are dissected off the undersurface of the left hemisternum, and (3) when dissecting the pedicle from the mediastinal soft tissue pericardium and the heart.

Did you analyze the dissection process in each of your 17 patients in whom the left internal mammary artery graft was injured to see what caused the injury, and can you comment on how to avoid such an injury?

In regard to the challenge of cardioplegia in these patients, 
clearly, retrograde cardioplegia is a valuable technique, but it requires dissection and temporary occlusion of the mammary artery graft. Since last year I have used esmolol, an ultra-shortacting $\beta$-blocking agent, on cardiopulmonary bypass to create electromechanical arrest. One of the groups of patients for which I have used this technique is patients undergoing redo operations with patent IMAs. Basically, a status of normothermic, nonischemic cardiac arrest is created. The local control of bleeding at the site of coronary arteriotomy is done by proximal and distal control with the use of small vessel loops. The results with the use of this technique, in general, have been satisfying, and, in several cases of reoperation in patients with old patent mammary artery grafts, the results have been particularly pleasing.

Dr. Lytle. Let me start with the first question. Having completed this study, we certainly would agree that a patent ITA graft does not increase the risk of a reoperation. There are a number of reasons for that. First, the patient that comes to reoperation with a patent IMA graft is much more likely to have a functioning anterior wall. Second, atherosclerotic embolization does not occur from ITA grafts. So despite the fact that it is technically more difficult to reoperate on a patient with a patent ITA graft, it is actually a safe reoperation.

The ease of dissecting out a patent ITA graft at reoperation is related to how the first operation was done. I think it is important during primary operation to divide the pericardium posteriorly and to have reasonably short IMA grafts that lie posteriorly and lateral to the pulmonary artery so that the lung covers them and they are not stuck to the sterum. The only situation where the ITA graft is dangerous is when it is stuck to the sternum, particularly when it is near the midline. In all other situations there are fairly straightforward ways to handle patent ITA grafts. About half of the patients in this study had their first operation some place other than the Cleveland Clinic, so the position of the grafts was variable.

One of the situations where retrograde cardioplegia has been a tremendous advantage has been for patients with patent ITA grafts. In the days before we had retrograde cardioplegia what we used to do would be to use a lot of systemic hypothermia, to $20^{\circ} \mathrm{C}$, to allow protection of the anterior wall with cold blood. That strategy is effective but requires more time for cooling and rewarming. With the use of retrograde cardioplegia, we can dissect out the ITA graft, put a clamp on it, and then use retrograde cardioplegia to protect its distribution. Retrograde cardioplegia makes reoperative procedures for patients with patent ITA grafts more convenient.

With regard to reoperation for patients with multiple ITA grafts, 15 patients in this study had multiple previous ITA grafts and one in-hospital death occurred in that subgroup. I do not think that that was a real increase in risk because a couple of these cases were emergencies. However, if we had to reoperate on a large group of patients with right ITA in situ grafts that crossed the midline, there would be more trouble with that situation that there would be for a group of patients with only patent left ITA grafts to left-sided vessels.

\section{Appendix 1. Variables tested for influence on in-hospital risk}

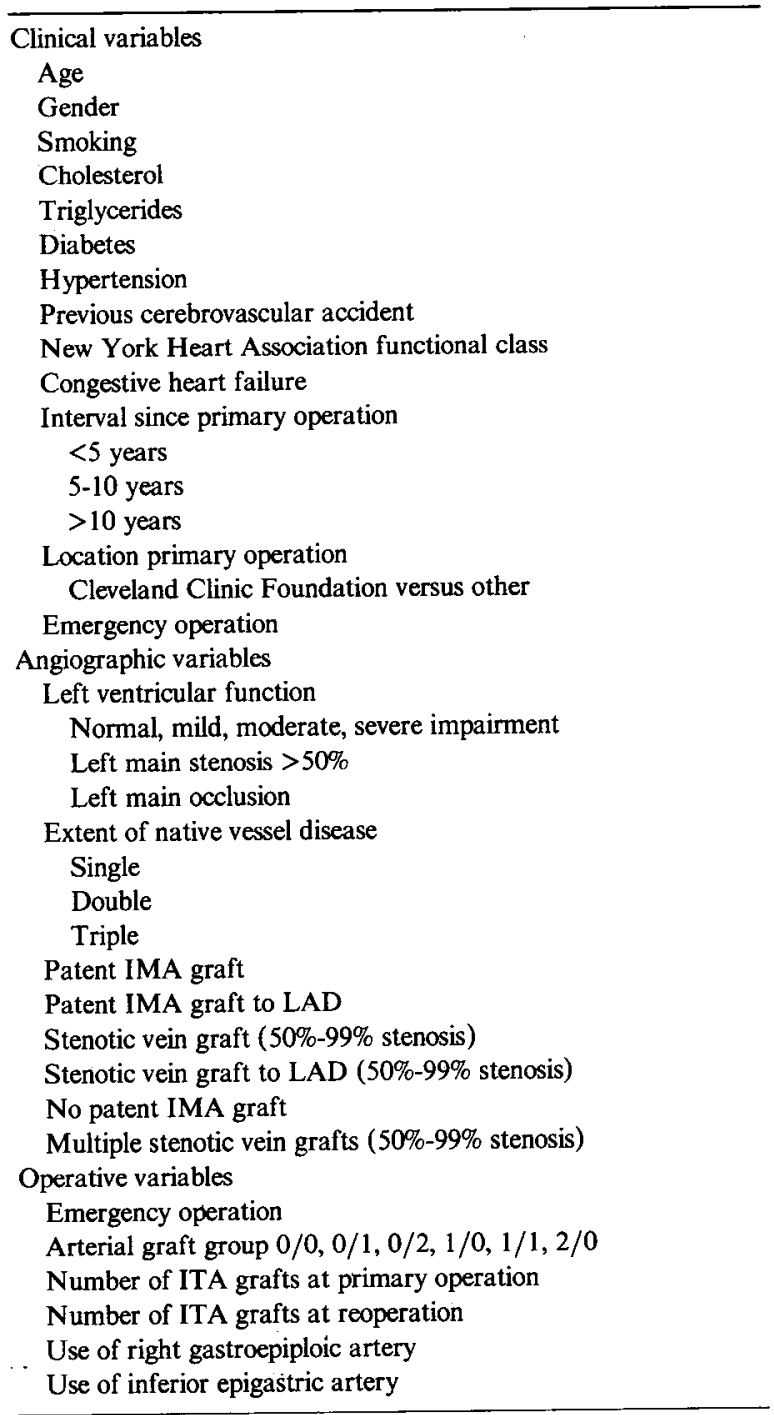

When patent ITA grafts were damaged during reoperation, there were no deaths in that group of patients, so it was not a disastrous occurrence. ITA grafts were injured during a variety of stages of the procedures, so there was no consistent pattern. Dissecting our patent ITA grafts requires much care. When we damage an ITA graft, it is usually a mistake. Fortunately, our mistakes are getting less common with the passage of time, but the risk is not zero. 